\title{
The mediation role of perceived social support in the relationship between interpersonal competence and self-esteem in married individuals
}

\author{
Kemal Baytemir ${ }^{1 \cdot A, B, C, D}$, Ayşe Sibel Demirtaşs ${ }^{2 \cdot D, E, F}$, Mehmet Ali Yıldız $z^{3 \cdot D, F}$ \\ 1: Amasya Üniversitesi, Turkey \\ 2: Alanya Alaaddin Keykubat Üniversitesi, Turkey \\ 3: Adıyaman Üniversitesi, Turkey
}

BACKGROUND

The main purpose of this research is to examine the mediation role of perceived social support in the relationship between interpersonal competence and self-esteem in married individuals.

\section{PARTICIPANTS AND PROCEDURE}

The study group of the research consisted of a total of 237 married individuals, 117 females and 120 males aged from 18 to 65 . The mean age of participants in the study was 39.34 $(S D=9.48)$. In order to gather data Interpersonal Competence Scale, Multidimensional Perceived Social Support Scale and Rosenberg Self-Esteem Scale were used as measures.

RESULTS

According to the results of this study, interpersonal competence predicts perceived social support and self-esteem, and perceived social support predicts self-esteem. Perceived social support, which is the main focus of the research, plays a partial mediation role in the relationship between interpersonal competence and self-esteem.

\section{CONCLUSIONS}

We think that when married individuals increase their interpersonal competencies they feel that they are able to communicate more effectively. A married individual who is able to build close relationships with family and friends, and who perceives support, will feel that they are not alone so they consider themselves as a person of worth and their self-esteem will increase.

\section{KEY WORDS}

interpersonal competence; social competence; perceived social support; self-esteem; married individuals

CORRESPONDIng AUthor - Kemal Baytemir, Ph.D., Amasya Eğitim Fakültesi, Amasya Üniversitesi, 05100 Amasya, Turkey, e-mail: kemalbaytemir@gmail.com

AUthors' CONTRiButions - A: Study design - B: Data collection - C: Statistical analysis - D: Data interpretation .

E: Manuscript preparation · F: Literature search · G: Funds collection

to Cite this ARTICLE - Baytemir, K., Demirtaş, A. S., \& Yıldız, M. A. (2018). The mediation role of perceived social support in the relationship between interpersonal competence and self-esteem in married individuals. Current Issues in

Personality Psychology 6(3), 200-211.

RECEIVED 23.11.2017 · REVIEWED 18.01.2018 · ACCEPTED 12.04.2018 · PUBLISHED 30.05.2018 


\section{BACKGROUND}

The achievement of intimacy in a close relationship is considered to be one of the critical developmental tasks in adulthood (Conger, Cui, Bryant, \& Elder, 2000). Murray, Holmes, and Griffin (2000) indicate that romantic relationships provide a unique perspective to study self-esteem because in "no other adult context is the possibility of acceptance more self-affirming" ( $p$. 479). Researchers have found that self-esteem is an important indicator of quality of life and has been linked to physical and psychological functioning (i.e. Diener \& Diener, 1995; Kuppens, Realo, \& Diener, 2008; Sarwer, Thompson, Mitchell, \& Rubin, 2008).

Marriage relationships are often conceptualised as an important source of self-esteem (Murray, Griffin, Rose, \& Bellavia, 2003). Self-esteem was defined as a "positive or negative attitude toward... the self" by Rosenberg (1965, p. 30). People's sense of their own self-worth is bound up in the quality of their relationships with others so that signs of rejection can threaten self-esteem (Leary \& Baumeister, 2000). Empirical studies that focused on self-esteem in marriage (Wiggins \& Lederer, 1984; Luteijn, 1994; Schafer $\&$ Keith, 2001) indicated that marital satisfaction is positively related to self-esteem. A positive correlation has been demonstrated by researchers between global indexes of self-esteem and sexual and marital satisfaction (e.g. Luteijn, 1994). McDonald, Ebert, and Mason (1986) indicated that people in intact marriages had higher self-esteem compared to those who were divorced. High self-esteem in marriage was also found to be associated with marital satisfaction and life satisfaction (Ylldız \& Baytemir, 2016). Indeed, considerable evidence suggests that high self-esteem is beneficial in romantic relationships. A study conducted by Erol and Orth (2016) on couples indicates that high self-esteem has a positive effect on the partner's happiness with the relationship. Furthermore, in romantic relationships, self-esteem has a correlation with relationship perception (Klosterman, 2012). It would be valuable to extend the understanding of self-esteem in marriage beyond these findings in literature.

Marriage is a primary relationship, often considered distinct from other family relationships because it is long-term, affords a central role identity, and provides a fundamental resource of social support (Akamatsu, Stephens, Hobfoll, \& Crowther, 1992). Given that spousal support is a key element of marital well-being, researchers have created a respectable body of literature trying to understand how husbands and wives provide support to their partners (Neff \& Karney, 2005). Cutrona (1996) defines social support "most generally as responsiveness to another's needs and more specifically as acts that communicate caring; that validate the other's words, feelings, or actions; or that facilitate adaptive coping with problems through the provision of information, assistance, or tangible resources" (p. 10). Social support includes emotional support (expressions of love, empathy, and concern), esteem support (respect for the person's qualities), information support (advice, appraisal of the situation), and tangible assistance (assistance with tasks or physical resources, such as money or a place to live) (Cutrona, 1996). Perceived social support differs from social support as the perception of spouses regarding the availability or adequacy of support provided by the partner. Our health and happiness are somehow linked to the supportive connections we maintain with others (Dehle, Larsen, \& Landers, 2001). Cotton (1999) has suggested that most adults meet their social needs through marriage. Marriage allows individuals numerous opportunities to provide support to a spouse. It provides opportunities for greater social support by utilising resources and built-in relationships through immediate and extended family members, such as children, spouses, inlaws, and family-of-origin. Research has shown that spouses reporting greater partner support are more satisfied with their marriages than those reporting less support (Julien \& Markman, 1991; Katz, Beach, \& Anderson, 1996). Emotional support, which is conceptualised as expressions of care, concern, love, and interest, especially during times of stress or upset, is primarily studied in close relationships (Cutrona \& Russell, 1990). The findings of the research done by Devoldre, Davis, Verhofstadt, and Buysse (2010) indicated that different facets of dispositional empathy do seem to play distinctive, meaningful roles in shaping support provision in marriage. Allgood, Crane, and Agee (1997) found that when husbands and wives had emotional support each other, marital satisfaction was increased.

It appears that perceived social support needs to be considered in the study of self-esteem in marriage relationships. Social support is an important variable because of its positive role in personal adjustment and health (Thoits, 2011; Baumeister \& Leary, 1995). Perceptions of social support in romantic relationships significantly predicts self-esteem and perceptions of the quality of relationship (Gurung, Sarason, \& Sarason, 1997). A study conducted by Hirniak (2016) demonstrated that perceptions of a romantic partner's self-esteem were positively associated with people's willingness to share problems with their partner and solicit support from them. There is evidence that romantic relationships can positively influence low self-esteem, because these relationships provide access to ongoing positive social feedback and emotional support (Edwards, 2017).

The abilities of spouses to communicate in the context of providing and receiving support is an important domain for understanding what leads marriages to succeed and fail (Sullivan, Pasch, Eldridge, \& Bradbury, 1998). Don and Hammond (2017) implied that 
support seekers who were autonomously motivated tended to seek support in a more direct and positive manner. In this connection, interpersonal competence is valuable because it allows the researcher to compare adjustment to intimate relationships such as marriage with adjustment to more general social relationships (Filsinger, 1980). Emotional and social competencies often help transmit important information about people's thoughts and intentions, and may help considerably in close personal relationships (Lopes et al., 2004). The results of the research done by Villa and Del Prette (2013) revealed a significant correlation confirming the relationship between marital satisfaction and the social competences of married couples. For the purpose of the current research, Buhrmester et al.'s (Buhrmester, Furman, Wittenberg, \& Reis, 1988) definition and operationalisation of interpersonal competence was used because it offers a comprehensive description by exploring competence across five interpersonal task domains: (1) initiating relationship (one's ability to initiate social activities with others asserting influence), (2) self-disclosure (sharing personal information with others), (3) emotional support (one's ability to show genuine empathy when a companion is experiencing problems or difficulties), (4) asserting influence (the ability to stand-up for oneself when necessary and refuse unreasonable demand), and (5) conflict resolution (one's ability to work through disagreements with others in a healthy way). People with good interpersonal competence have greater chances to develop satisfying marital relations and to build a network of social support (Buhrmester et al., 1988) and also have greater life satisfaction, environmental mastery, self-efficacy in social situations, hope, happiness, and quality of life (Segrin \& Taylor, 2007). Self-disclosure is an important aspect of communication in most close relationships (Derlega, Metis, Petronio, \& Margulis, 1993). Regarding couples' relationships, researchers have discovered that whenever one spouse has a lower level of emotional expressiveness than the other, a decrease in marital satisfaction may result (Yelsma \& Marrow, 2003). Sprecher and Hendrick (2004) found positive associations between self-disclosure and the individual characteristics of self-esteem and relationship esteem. The results of research done by Villa and Del Prette (2013) revealed a significant correlation confirming the relationship between marital satisfaction and the social skills of married couples. Researchers have also demonstrated that couples' communication is consistently and significantly related to couples' satisfaction (Carrère \& Gottman, 1999; Gottman $\&$ Levenson, 1992). These results were substantiated in a study conducted by Greeff and Bruyne (2000) in which 57 couples participated. The results showed that the collaborative conflict management style has the highest correlation with marital satisfaction.
Effective communication as an interpersonal competence is a fundamental contributor to a satisfying marriage. Given that individuals with high levels of interpersonal competence exhibit effective communication behaviour (Spitzberg \& Cupach, 1989), the individual is able to meet these needs better than those with low levels of interpersonal competence. As Schwalbe and Staples (1991) have expressed, the feedback of men and women about their interactions constitute an important resource for their self-esteem.

Given the existing theory and the empirical literature reviewed above, we suggest that perceived social support has a mediating role in the relationship between interpersonal competence and self-esteem in married individuals. Because people with high interpersonal competence have environmental mastery and self-efficacy in social situations (Segrin \& Taylor, 2007), they have a greater chance to develop satisfying marital relations and to build a network of social support (Armistead et al., 1995; Buhrmester et al., 1988) and have high self-esteem (Goodwin et al., 2004), it is suggested that perceived social support has a mediating role in the relationship between interpersonal competence and self-esteem in married individuals. Based on this suggestion, the following hypothesis was formulated:

Hypotheses for the purpose of the study:

- There is a direct positive relation between interpersonal competence and perceived social support.

- There is a direct positive relationship between perceived social support and self-esteem.

- There is a direct positive relationship between interpersonal competence and self-esteem.

Interpersonal competence enhances perceived social support and shows indirect and positive relations with self-esteem.

\section{PARTICIPANTS AND PROCEDURE}

\section{RESEARCH DESIGN}

Correlational research design was used in this study. Correlational research is used to examine the relations between variables without attempting to affect the relation between two or more variables (Fraenkel, Wallen, \& Hyun, 2012). This study defines the relation between married individuals' interpersonal competence, perceived social support, and self-esteem.

\section{SAMPLE}

Convenience sampling was used for the study group. The study group of the research consisted of a total of 237 married individuals, 117 females and 120 males, living in a province in the Black Sea region. The mean 
age of study participants was $39.34(S D=9.48)$. The distributions of the individuals in terms of age was as follows: 50 individuals between ages 18 and 30 years, 90 individuals between 31 and 40 years, 71 individuals between 41 and 50 years, and 26 individuals at the age of 51 years and above. The distributions of the individuals in terms of education level were as follows: 49 respondents had a primary education, 61 respondents had a high school education, 88 respondents had an undergraduate or a bachelor's degree, and the remaining 39 respondents had postgraduate education. Also, the respondents answered the question of how long have they been married: 33 respondents declared 0-2 years, 60 respondents 3-8 years, 34 respondents 9-15 years, 42 respondents $16-20$ years, and 68 respondents for 21 years and above. The respondents answered the question of how many children they have: 42 respondents came from families with no children, 41 respondents with one child, 91 respondents with two children, 48 respondents with three children, 12 respondents with four children, and three respondents with five and above children.

\section{DATA COLLECTION TOOLS}

The Interpersonal Competence Scale (ICS) developed by Buhrmester et al. (1988), to measure interpersonal competence within close friendship relations and adapted into Turkish Culture by Baytemir (2014); the Rosenberg Self-Esteem Scale (RSES) was originally developed by Rosenberg (1965) to evaluate individual self-esteem and adapted into Turkish Culture by Cuhadaroğlu (1986); and the Multidimensional Scale of Perceived Social Support (MSPSS) developed by Zimet, Dahlem, Zimet, and Farley (1988), to measure perceptions of support from three sources: family, friends, and a significant other, and adapted into Turkish Culture by Eker and Arkar (1995).

Interpersonal Competence Scale (ICS). In order to measure interpersonal competence in close friendship relations, Buhrmester et al. (1988) developed a fivepoint Likert-type scale measuring five domains of personal competence (initiating relationship, asserting influence, conflict resolution, self-disclosure, providing emotional support). The scale consists of a total of 40 items with eight items in each dimension. The Turkish adaptation of the scale was carried out on a group of adolescents by Baytemir (2014). The validity of the structure of the scale was verified, the criterion validity study with similar scales and the appropriate values were obtained in the reliability calculations. The validity and reliability study of the scale with university students was performed by Baytemir (2016b). Confirmatory factor analysis conducted to test the scale construct validity showed that the scale produced adequate fit indices $\left(\chi^{2} / d f=2.27\right.$, RMSEA $=.06$, $\mathrm{SRMR}=.08, \mathrm{CFI}=.97, \mathrm{NFI}=.94, \mathrm{TLI}=.96)$. In the cri- terion validity study, correlation coefficients between Interpersonal Competence Scale and the Perceived Social Competence Scale were .70. In the reliability calculations Cronbach $\alpha$ values varied between .79 and .86 for sub-dimensions and .94 for overall scale. In this study, the Cronbach $\alpha$ value for the interpersonal competence scale was .89.

The Rosenberg Self-Esteem Scale (RSES) was originally developed by Rosenberg (1965) to evaluate individual self-esteem. The original form of the RSES is a 63-item and 12-sub-scale instrument. The first subscale of the RSES is used to measure self-esteem. In this research, the first sub-scale was used. Respondents complete the scale by indicating their agreement with each of 10 statements involving five positively worded statements and five negatively worded statements. All items are answered using a four-point Likert scale format ranging from strongly agree to strongly disagree. The range of scores is $0-40$, with a score of 40 indicating the highest level of self-esteem and 10 the lowest level. High scores indicate high self-esteem. The adaptation into Turkish culture of the RSES was done by Çuhadaroğlu (1986). After establishing language, the validity of the scale and reliability of the analysis were examined. Test-retest reliability coefficients for the scale varied between .46 and .89. A criterion-related validity study was done by Symptom Distress Check List (SCL-90-R) and the correlations results varied between .45 and .70. Also, it was found that the average self-esteem score of normal individuals and psychiatric patients had some differences with favour of the normal group, so theoretical structure validity was supported. RSES was used by Yıldız and Baytemir (2016) in a study on married individuals. The Cronbach $\alpha$ value for the self-esteem scale in their study was .88. Confirmatory factor analysis conducted to test the scale construct validity showed that model-data fit values were above acceptable levels $\left(\chi^{2} / d f=2.99, \mathrm{RMSEA}=.08, \mathrm{RMR}=.04\right.$, $\mathrm{SRMR}=.06, \mathrm{GFI}=.94, \mathrm{AGFI}=.89, \mathrm{CFI}=.93, \mathrm{NFI}=.90$, and NNFI $=.90$ ). The Cronbach $\alpha$ value for the self-esteem scale in this study was .88 .

Multidimensional Scale of Perceived Social Support (MSPSS). The Multi-Dimensional Perceived Social Support Scale was developed by Zimet et al. in 1988 and adapted into Turkish Culture, validity and reliability studies by Eker and Arkar (1995) and Eker, Arkar, and Yaldiz (2001). The Multidimensional Scale of Perceived Social Support (MSPSS) is a brief research tool designed to measure perceptions of support from three sources: family, friends, and a significant other. The scale is comprised of a total of 12 items, with four items for each subscale. The generalisability of the factorial structure was confirmed. The internal consistency figures for the subscales and the total scale were high. The subscales and the total scale score correlated in the expected direction with measures of social support, loneliness, hopelessness, negative social interaction, and 
a symptom check list, particularly in the psychiatry and the surgery samples. Correlation results and group comparisons contributed to the construct validity of the MSPSS (Eker et al., 2001). The Cronbach $\alpha$ value for the perceived social support scale in this study was .88 .

\section{PROCEDURE}

The data required for the study were collected from married individuals. First, the purpose of the study was explained and they were asked whether they would contribute to the research or not. Individuals who volunteered to participate in the survey were given the scales. The participants were individuals from various government agencies. Scale applications were sometimes performed in groups and sometimes on an individual basis. It was stated that the names should not be written on the scale and the study serves scientific purposes and all the information is private. Data collection lasted approximately 25 minutes.

\section{DATA ANALYSIS}

The data were analysed through SPSS 21.0 and LISREL 8.8 statistical software programs. First, the collected data were reviewed for incorrect coding, and incomplete or blank data were excluded from the analysis. In order to find out whether there were outlying values disturbing assumptions of "linearity" and "normality" within the data obtained from the sample, Mahalanobis distance values were calculated. Twelve observations (multivariate outliers) with Mahalanobis value larger than $\left(\chi_{8: 01}^{2}=20.09, p<.001\right)$ were excluded. Histogram graphs of the variables were checked for normality, and non-normally distributed variables were observed. In addition, the values of skewness and kurtosis were examined to determine whether the data had a normal distribution. The skewness and kurtosis values were found varying between -1 and +1 (see Table 1 ). When correlations between variables were examined, it was observed that the correlation values were mostly moderate (see Table 1) and ranged from .04 to .80 , so there was no multiple connection problem. In the analysis of the data, the relations between the variables were examined by Pearson correlation method and the mediating relationship by structural equation modelling.

Structural Equation Modelling (SEM) is a general statistical modelling technique widely used in behavioural sciences. SEM can be seen as a combination of factor analysis and path analysis or regression analysis. Structural equation modelling refers to things represented by latent factors (Hox \& Bechger, 1998). In this study, because self-esteem was measured with one-dimensional structure, indicators were needed to show that the structural equation model is concealing, and a parcelling path has been made for this. According to Bandalos and Finney (2001), the use of substance parcels in SEM studies has become widespread in recent years. The platform application involves averages or sums of two or more items and the average or sum of the results is used as a basic unit of analysis in the SEM. An advantage of the use of item parcels is that parcels have a more continuous distribution and a more normal distribution than individual items and are thus more well suited to the common assumptions of normal theory-based estimation methods such as maximum likelihood (ML) (Bandalos \& Finney, 2001). According to Kocayörük (2012), the main purpose of using the parcels obtained in this way is to allow all the observed variables to be evaluated at the highest level of the representation power of the implicit variable. Firstly, during the parcels, the factor load values of each item were looked up and sorted from the highest to the lowest. Then, the largest factor was assigned to the parcels equally according to the factor load value, starting from the load values. Accordingly, the first parcels $10,5,6,1$, and 2 and the second parcels 9, 3, 7, 4 , and 8 were assigned.

Before the structural model was tested, the measurement model was tested. The two-step approach proposed by Anderson and Gerbing (1988) for mediation analysis was used. First, it was ascertained whether the measurement model produces acceptable adaptation values. If the acceptable model values result in acceptable measurement values, the structural model is tested. In other words, it is necessary to verify the structures to be examined before going into the structural pattern.

\section{MEASUREMENT MODELS FOR LATENT VARIABLES}

First, the measurement model was tested. The results of the measurement model developed for the purposes of the study are given in Figure 1.

Upon looking at the measurement model results for examining the proposed model, we found that all $t$ values were significant (ranging from 4.56 to 16.94). As shown in Figure 1, it has been found that the standardised path coefficients vary between .31 and .98 and are sufficient. When the model fit values were analysed at the first stage of the analysis, it was found that the fit measures were adequate but the RMSEA value was .11. When the sub-dimensions of the interpersonal competence in relation to the modification proposal were correlated as seen in the figure, the model's criteria was found to be sufficient $\left(\chi^{2} / d f=2.47\right.$, RMSEA $=.08, \mathrm{CFI}=.97, \mathrm{NFI}=.95$, $\mathrm{GFI}=.94)$. 


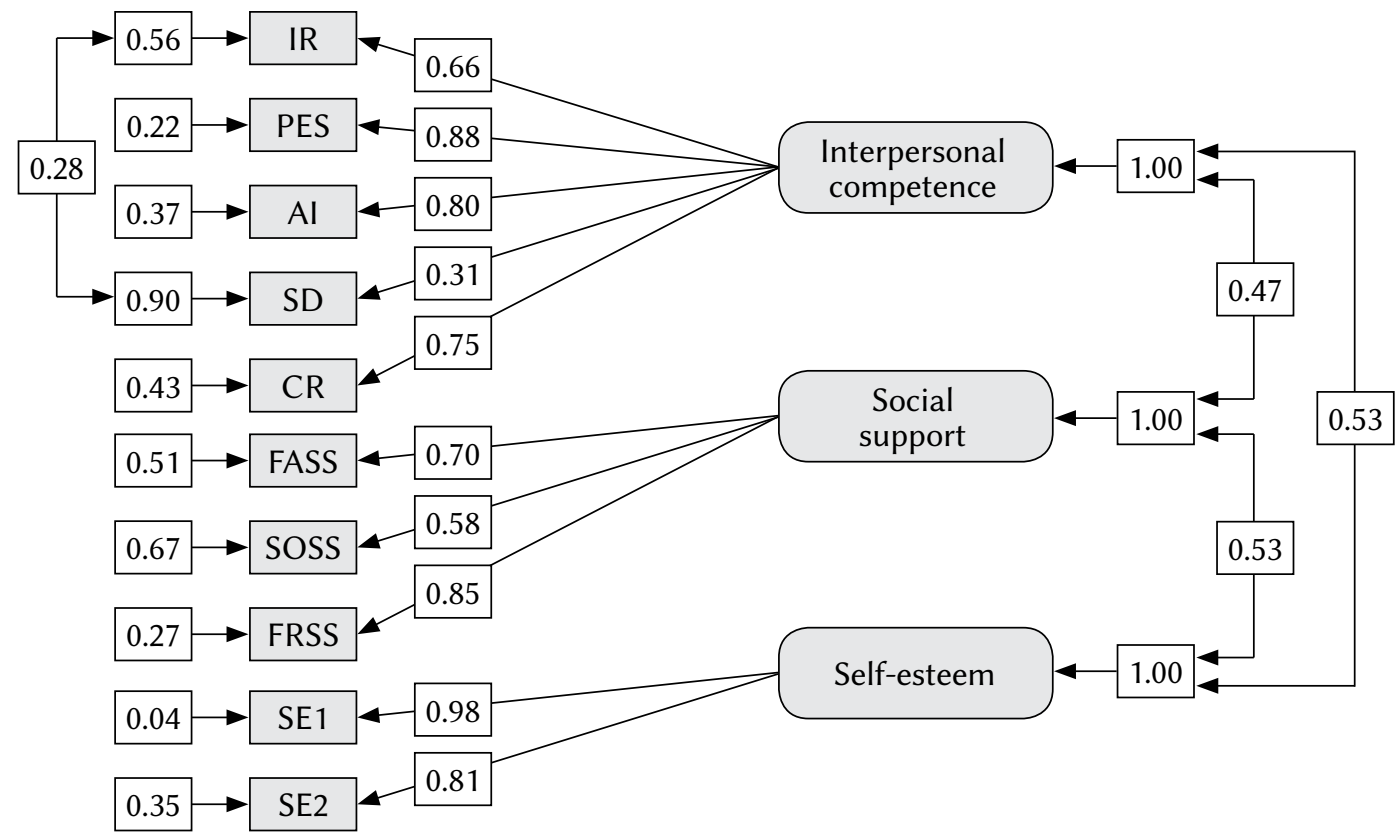

Note. IR - Initiating relations, PES - Providing emotional support, AI - Asserting influence, SD - Self-disclosure, CR - Conflict resolution, FASS - Perceived social support from family, SOSS - Perceived social support from special person, FRSS Perceived social support from friends, SE1 - Self-esteem 1, SE2 - Self-esteem 2

Figure 1. Standardised path coefficients associated with hypothesis measurement model.

Table 1

Arithmetic mean, standard deviation, skewness, and kurtosis coefficients related to variables in the model

\begin{tabular}{lccccc}
\hline Variables & $N$ & $\bar{X}$ & $d f$ & $\begin{array}{c}\text { Skew- } \\
\text { ness }\end{array}$ & Kurtosis \\
\hline Initiating relations & 237 & 25.44 & 5.56 & .00 & -.02 \\
Providing emotional support & 237 & 28.96 & 5.32 & .00 & -.05 \\
Asserting influence & 237 & 28.19 & 5.39 & -.01 & -.06 \\
Self-disclosure & 237 & 22.03 & 5.11 & .00 & -.02 \\
Conflict resolution & 237 & 27.84 & 4.91 & .00 & -.01 \\
Perceived social support from family & 237 & 23.42 & 4.45 & -.34 & -.60 \\
Perceived social support from special person & 237 & 19.20 & 6.44 & -.06 & -.47 \\
Perceived social support from friends & 237 & 21.33 & 5.01 & -.15 & -.41 \\
Self-esteem 1 & 237 & 16.57 & 2.39 & -.18 & -.48 \\
Self-esteem 2 & 237 & 15.70 & 2.45 & -.04 & -.26 \\
\hline
\end{tabular}

\section{RESULTS}

\section{FINDINGS RELATING TO DESCRIPTIVE STATISTICS AND VARIABLES}

Arithmetic mean, standard deviation, skewness coefficient, kurtosis coefficient values of the indicators in the model are given in Table 1.
In Table 1 it can be seen that the values of kurtosis and skewness coefficient of the data belonging to study group are within normal limits ( +1 to -1 ). Accordingly, it can be said that the data have a normal distribution.

Pearson correlation analysis was used to determine the relationships between the indicators in the study. The findings are presented in Table 2 .

As can be seen in Table 2, while there was no significant relationship between self-disclosure from sub-di- 
Table 2

Correlation values related to variables in the measurement model

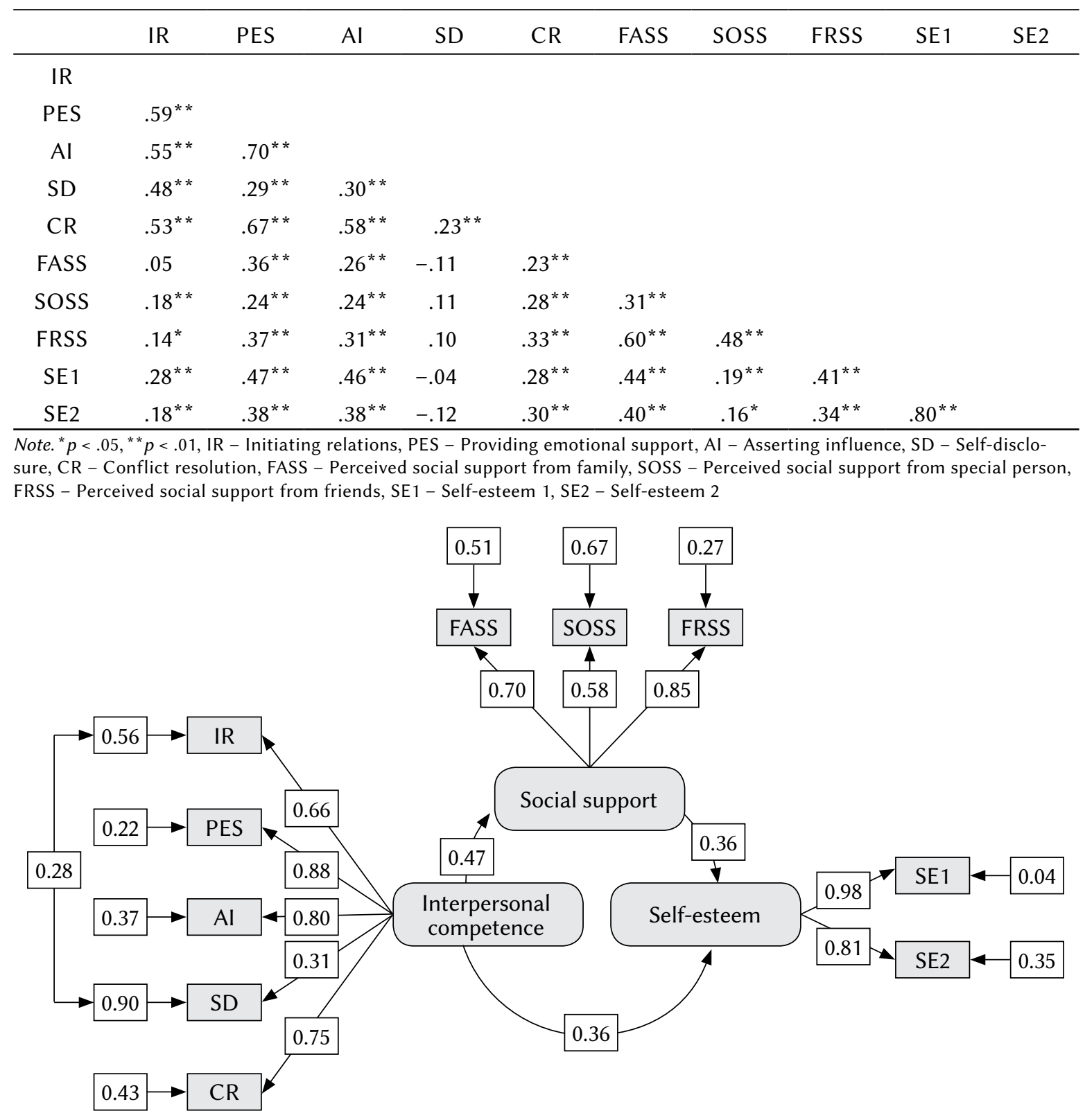

Note. IR - Initiating relations, PES - Providing emotional support, AI - Asserting influence, SD - Self-disclosure, CR - Conflict resolution, FASS - Perceived social support from family, SOSS - Perceived social support from special person, FRSS - Perceived social support from friends, SE1 - Self-esteem 1, SE2 - Self-esteem 2

Figure 2. Standardised path coefficients associated with the structural model.

mensions of interpersonal competence and social support perceived by the family, by the special person, and the friend, there was positive, weak, and moderately significant relationship between the other variables.

\section{STRUCTURAL EQUATION MODEL ANALYSES}

When we look at the results of the structural model to examine the proposed model, it can be seen that all the $t$ values are significant (varying between 4.72 and 16.27). The analysis results for the structural model are shown in Figure 2, and the model fit indices are given in Table 3.

As can be seen in Figure 2, it was found that the Standardised path coefficients vary between .36 and .98 and are sufficient. The model fit indices are presented in Table 3.

As seen in Table 3, the structural model produced good and acceptable values. According to the method 
Table 3

Adjustment values associated with structural model

\begin{tabular}{lcccccc}
\hline Model fit indices & $\chi^{2} / d f(76.56 / 31)$ & RMSEA & SRMR & CFI & NFI & GFI \\
\hline Values & 2.30 & .08 & .07 & .97 & .95 & .94 \\
\hline
\end{tabular}

of Baron and Kenny (1986), certain conditions must be met for the mediator relationship to be possible. The first condition, when examined by the measurement model, is related to self-esteem, which is the outcome variable of interpersonal competence. The second condition is that the interpersonal competence, which is the antecedent variable, is associated with the mediator variable social support. The third condition is about social support and self-esteem. The model provides all the conditions Baron and Kenny (1986) specified in the method. It is expected that the relationship between interpersonal competence and self-esteem decreases or is completely meaningless when the influence of the social support variable is controlled. When we look at the standardised coefficient, we see that the path to self-esteem from perceived social support falls to 36 but the $t$-value is significant.

When the total effects are examined, the total effect of interpersonal competence was found on perceived social support $.47(t=5.73, p<.001)$ and on self-esteem $.53(t=8.17, p<.001)$. When the indirect effects are examined the indirect effect of interpersonal competence on self-esteem was found .17 $(t=3.97, p<.001)$. In this case, it can be said that social support plays a partial mediator role between interpersonal competence and self-esteem.

\section{DISCUSSION}

The purpose of this study was to examine the mediating role of perceived social support in the relationship between interpersonal competence and self-esteem in married individuals. The results of the current study showed that interpersonal competence predicts perceived social support, and perceived social support predicts self-esteem in married individuals. In the current study, the mediating role of perceived social support in the relationship between interpersonal competence and perceived social support was found to be statistically significant. Thus, the hypotheses put forward in the research were supported.

In literature, interpersonal competence is an enormously broad notion. Spitzberg and Cupach (1989, p. 5) indicated that "Social skills, communication competence, social intelligence, empathy, assertiveness, adjustment, and a host of other constructs are inextricably affiliated with the study of competence in interpersonal relations". In this sense, this finding confirms earlier studies in literature. Don and Hammond (2017) investigated how differences in relationship autonomy predicted the behaviour and outcomes of couples in support interactions. The findings revealed that support seekers who were autonomously motivated tended to seek support in a more direct and positive manner, which in turn promoted greater levels of emotional, informational, and tangible support from their partners. In another study, Anders and Tucker (2000) found that individuals with insecure attachment style had smaller social support networks. The fact that individuals have smaller social support networks is explained by the weakness of interpersonal competencies. In light of the literature, it is considered that people with good interpersonal competence have a greater chance of developing satisfactory marital relations and to build a network of social support (Armistead et al., 1995). In contrast, individuals with low interpersonal competence are less likely to seek support from a partner and less likely to offer support to partner.

In line with the previous research, the results of this study indicate that perceived social support is correlated with self-esteem. Social support is an important variable because of its positive role in personal adjustment and health (Thoits, 2011; Baumeister \& Leary, 1995). In a study conducted by Pugliesi (1985), marriage was found to increase social support, with social support positively affecting self-esteem and well-being. Schneider (2000) investigated the psychosocial conditions including social support and self-esteem in stress in infertile couples. Qualitative results supported the significant contribution of self-esteem to stress and explained ratings of social support and perceived stress. It appears that perceived social support has an important role considered in the study of self-esteem in marriage relationships. Research revealed that the perceptions of social support in romantic relationships significantly predict self-esteem and perceptions of the quality of the relationship (Gurung et al., 1997). There is evidence that romantic relationships can positively influence low self-esteem because these relationships provide access to ongoing positive social feedback and emotional support (Edwards, 2017).

Individuals who receive support from partners during times of need or who perceive that there is someone they can rely on are likely to have a high level of marital satisfaction and self-esteem. One 
explanation of this relationship is that the feedback from partners about their interactions constitute an important resource for their self-esteem in romantic relationships. There is evidence that satisfying romantic relationships can positively influence low self-esteem because these relationships provide emotional support and positive feedback from partners (Edwards, 2017). As the perceived social support from the partner increases, the self-esteem of the partner increases. Married individuals who think they are supported by the partner consider themselves as more valuable and lovable.

Consistent with the literature, the current research revealed that married individuals with high interpersonal competence have higher self-esteem. In many studies interpersonal competence, social skill, or social competence was significantly related to self-esteem (Larson et al., 2007; Riggio et al., 1990). Research on interpersonal competence indicates that individuals with high interpersonal competence have more positive relationships (Armistead et al., 1995; Buhrmester et al., 1988) and are happier (Baytemir, 2016a). Consistent with the looking-glass theory of the self (Cooley, 1902), Schwalbe and Staples (1991) showed that both men and women rate reflected appraisals (i.e. the way others react to them) as an important source of self-esteem. Individuals with a high level of interpersonal competence are considered to have more positive and rewarding relationships as they have behaviours that cause others give them positive feedback (Yüksel, 1997), and this feedback enhances their self-esteem. A study conducted by Hirniak (2016) demonstrated that perceptions of a romantic partner's self-esteem were positively associated with people's willingness to share problems with their partner and solicit support from them.

The overall results of the study showed that the mediating role of perceived social support in the relationship between interpersonal competence and self-esteem on married individuals was statistically significant. Research on social support in marriage indicates that there is a link between marital satisfaction and social support (Acitelli \& Antonucci, 1994; Nawaz, Javeed, Haneef, Tasaur, $\&$ Khalid, 2014). According to the theory of marriage protection, marriage is a resource for social and emotional support (Booth \& Amato, 1991). The way spouses help each other cope with personal difficulties, and how they provide everyday support to one another, is an important domain for understanding how marriages succeed and fail (Bradbury \& Karney, 2004). The nature of support exchange within a marriage is special. Studies in medicine show that spouses provide more support of all types to patients than do other members of the close social network (Sherbourne \& Hays, 1990; Revenson, Schiaffino, Majerovitz, \& Gibofsky,
1991). The abilities of spouses to communicate in the context of providing and receiving support are an important domain for understanding the quality of relationships (Sullivan et al., 1998). One reason that perceived social support has a mediating role in the relationship between interpersonal competence and self-esteem is because it can serve as an act of relationship maintenance. Relationship maintenance is the process that can be described as all the behaviours that keep relational partners satisfied and that contribute to relationship continuation (Sprecher \& Hendrick, 2004). In respect of couple relationships, researchers have discovered that whenever one spouse has a lower level of emotional expressiveness than the other, a decrease in marital satisfaction may result (Yelsma \& Marrow, 2003). Interpersonal competence, such as self-disclosure and emotional support, contributes to a sense of intimacy in relationships, which is fundamental to relationship quality (Prager, 2000). Recognising shared values and characteristics might improve the perceived social support of partners and overall relationship quality because these qualities concern the couple as a unit (Edwards, 2017). Effective communication in marriage positively influences partners' self-esteem through being appreciated and supported. Consistent with Cooley's (1902) looking-glass theory of the self, the feedback from the partners plays an important role as a source of self-esteem.

Before concluding, it is worth acknowledging some limitations of the current research. Although the research has reached its aims, there was a limitation about the participants. Participants of the current research were chosen through convenience sampling method and consisted of couples within a region. Participants from different cities or regions would have increased the generalisability of the research findings. The other limitation of the research is the cross-sectional nature of the data. Another limitation is that the age range of the participants was very wide. For example, it could be limited to the first five years of marriage. While the models indicate potential directions of the relationships between the variables, causality cannot be determined. In future research, longitudinal studies are needed to investigate complex causal relationships.

Notwithstanding this limitation, the present research contributes to the understanding the relationships of interpersonal competence, perceived social support and self-esteem on married couples. Findings obtained from this study may be used for future studies of close relationships as well as for preventive counselling programs. Furthermore, our findings have practical implications for self-esteem promotion, suggesting that interventions focused on interpersonal competence might enhance perceived social support, and increase self-esteem. 
Thus, the study has the potential to provide useful insight for further research and for experts working within the field.

This study was presented in abstract form at the $5^{\text {th }}$ International Conference on Humanities, Social Sciences, Education and Interdisciplinary Studies, Fune, 2017, Bangkok, Thailand.

\section{References}

Acitelli, L. K., \& Antonucci, T. C. (1994). Gender differences in the link between marital support and satisfaction in older couples. Journal of Personality and Social Psychology, 67, 688-698.

Akamatsu, T. J., Stephens, M. A. P., Hobfoll, S. E., \& Crowther, J. H. (eds.). (1992). Series in applied psychology: Social issues and questions. Family health psychology. Washington, DC: Hemisphererp.

Allgood, S. M., Crane, D. R., \& Agee, L. (1997). Social support: distinguishing clinical and volunteer couples. The American Journal of Family Therapy, 25, 111-119.

Anders, S. L., \& Tucker, J. S. (2000). Adult attachment style, interpersonal communication competence, and social support. Journal of The International Association for Relationship Research, 7, 379-389. DOI: 10.1111/j.1475-6811.2000.tb00023.x

Anderson, J. C., \& Gerbing, D. W. (1988). Structural Equation Modeling in Practice: A Review and Recommended Two-Step Approach. Psychological Bulletin, 103, 411-423.

Armistead, L., Forehand, R., Beach, Steven, R. H., \& Brody, G. H. (1995). Predicting interpersonal competence in young adulthood: The roles of family, self, and peer systems during adolescence. Journal of Child and Family Studies, 4, 445460. DOI: $10.1007 / \mathrm{BF} 02237274$

Bandalos, D. L., \& Finney, S. J. (2001). Item parceling issues in structural equation modelling. In G. A. Marcoulides \& R. E. Schumacker (Eds.), New developments and techniques in structural equation modelling (pp. 269-296). Mahwah, NJ: Lawrence Erlbaum.

Baron, R. M., \& Kenny, D. A. (1986). The moderator-mediator variable distinction in social psychological research: Conceptual, strategic, and statistical considerations. Journal of Personality and Social Psychology, 51, 1173-1182.

Baumeister, R. F., \& Leary, M. R. (1995). The need to belong: Desire for interpersonal attachments as a fundamental human motivation. Psychological Bulletin, 117, 497-529. http://dx.doi. org/10.1037/0033-2909.117

Baytemir, K. (2014). The mediation of interpersonal competence in the relationship between parent and peer attachment and subjective well-being in adolescence. Dissertation thesis, Gazi University, Ankara, Turkey.

Baytemir, K. (2016a). The mediation of interpersonal competence in the relationship between parent and peer attachment and subjective well-being in adolescence. Education and Science, 41, 69-91.

Baytemir, K. (2016b). The study of validity and reliability of the interpersonal competence scale on university students. VI. International Canik Symposium (Psychological Counseling and Guidance Symposium). May, Samsun, Turkey.

Booth, A., \& Amato, P. R. (1991). Divorce and psychological stress. Journal of Health and Social Behavior, 32, 396-407. DOI: 10.2307/2137106

Bradbury, T. N., \& Karney, B. R. (2004). Understanding and altering the longitudinal course of marriage. Journal of Marriage and Family, 66, 862-879.

Buhrmester, D., Furman, W., Wittenberg, M. T., \& Reis, H. T. (1988). Five domains of interpersonal competence in peer relationships. Journal of Personality and Social Psychology, 55, 991-1008.

Carrère, S., \& Gottman, J. M. (1999). Predicting the future of marriages. In E. M. Hetherington (Ed.), Coping with divorce, single parenting, and remarriage: A risk and resiliency perspective (pp. 3-22). Hillsdale, NJ: Lawrence Erlbaum Associates.

Conger, R. D., Cui, M., Bryant, C. M., \& Elder, G. H., Jr. (2000). Competence in early adult romantic relationships: A developmental perspective on family influences. Journal of Personality and Social Psychology, 79, 224-237. http://dx.doi. org/10.1037/0022-3514.79.2.224

Cooley, C. H. (1902). Human nature and the social order. New York: Scribner.

Cotton, S. R. (1999). Marital status and mental health revisited: Examining the importance of risk factors and resources. Family Relations, 48, 225-233.

Cutrona, C. E. (1996). Social support in couples. Thousand Oaks, CA: Sage.

Cutrona, C. E., \& Russell, D. W. (1990). Type of social support and specific stress: Toward a theory of optimal matching. In B. R. Sarason, I. G. Sarason, \& G. R. Pierce (Eds.), Wiley series on personality processes. Social support: An interactional view (pp. 319-366). Oxford, England: John Wiley.

Çuhadaroğlu, F. (1986). Self-esteem on adolescents. Master's thesis, Hacettepe University, Ankara, Turkey.

Dehle, C., Larsen, D., \& Landers, J. E. (2001). Social support in marriage. The American Journal of Family Therapy, 29, 307-324.

Derlega, V. J., Metis, S., Petronio, S., \& Margulis, S. T. (1993). Self disclosure. Newbury Park, CA: Sage.

Devoldre, I., Davis, M., Verhofstadt, L., \& Buysse, A. (2010). Empathy and social support provision in couples: social support and the need to study the 
underlying processes. The Journal of Psychology, 144, 259-284.

Diener, E., \& Diener, M. (1995). Cross-cultural correlates of life satisfaction and self-esteem. Journal of Personality and Social Psychology, 68, 653-663.

Don, B. P., \& Hammond, M. D. (2017). Social support in intimate relationships: The role of relationship autonomy. Personality and Social Psychology Bulletin, 43, 1112-1124.

Edwards, J. (2017). Identifying positives within a negative self-image: What might low self-esteem individuals bring to romantic relationships? Western Undergraduate Psychology Journal, 5, 2.

Eker, D., \& Arkar, H. (1995). Çok boyutlu algılanan sosyal destek ölçeği'nin faktör yapısı, geçerlik ve güvenirliği [Factorial structure, validity, and reliability of the multidimensional scale of perceived social support]. Türk Psikoloji Dergisi, 34, 45-55.

Eker, D., Arkar, H., \& Yaldız, H. (2001). Çok boyutlu algılanan sosyal destek ölçeği'nin gözden geçirilmiş formunun faktör yapısı, geçerlik ve güvenirliği [Factorial structure, validity, and reliability of revised form of the multidimensional scale of perceived social support]. Türk Psikiyatri Dergisi, 12, 17-25.

Erol, R. Y., \& Orth, U. (2016). Self-esteem and the quality of romantic relationships. European Psychologist, 21, 274-283. http://dx.doi.org/10.1027/10169040/a000259

Filsinger, E. E. (1980). Social competence in short-and long-term relationships. Paper presented to the Theory Construction and Methods Preconference Workshop, Portland, Oregon (October).

Fraenkel, J. R., Wallen, N. E., \& Hyun, H. H. (2012). How to design and evaluate research in education ( $8^{\text {th }}$ ed.). New York: McGraw-Hill.

Goodwin, R., Costa, P., \& Adonu, J. (2004). Social support and its consequences: 'Positive' and 'deficiency' values and their implications for support and self-esteem. British Journal of Social Psychology, 43, 1-10.

Greeff, A. P., \& Bruyne, T. D. (2000). Conflict management style and marital satisfaction. Journal of Sex \& Marital Therapy, 26, 321-334. DOI: 10.1080/009262300438724

Gurung, R. A., Sarason, B. R., \& Sarason, I. G. (1997). Personal characteristics, relationship quality, and social support perceptions and behavior in young adult romantic relationships. Personal Relationships, 4, 319-339.

Hirniak, A. (2016). How perceptions of a relationship partner's self esteem influence support seeking. Master's thesis. Wilfrid Laurier University.

Hox, J. J., \& Bechger, T. M. (1998). An introduction to structural equation modeling. Family Science $R e-$ view, 11, 354-373.

Julien, D., \& Markman, H. J. (1991). Social support and social networks as determinants of individual and marital outcomes. Journal of Social and Personal Relationships, 8, 549-568.
Katz, J., Beach, S. R. H., \& Anderson, P. (1996). Self-enhancement versus self-verification: Does spousal support always help? Cognitive Therapy and Research, 20, 345-360.

Klosterman, M. (2012). Self-esteem and relationship perception. Ursidae: The Undergraduate Research Journal at the University of Northern Colorado, 2, 1-7.

Kocayörük, E. (2012). Self-determination theory and relationship between perception of parents and emotional well-being of adolescents. Turkish Psychological Counseling and Guidance Journal, 4, 24-37.

Kuppens, P., Realo, A., \& Diener, E. (2008). The role of positive and negative emotions in life satisfaction judgment across nations. Journal of Personality and Social Psychology, 95, 66-75.

Larson, J. J., Whitton, S. W., Hauser, S. T., \& Allen, J. P. (2007). Being close and being social: peer ratings of distinct aspects of young adult social competence. Journal of Personality Assessment, 89, 136148. DOI: 10.1080/00223890701468501

Leary, M. R., \& Baumeister, R. F. (2000). The nature and function of self-esteem: Sociometer theory. In M. P. Zanna (Ed.), Advances in experimental social psychology (vol. 32, pp. 2-51). San Diego, CA: Academic Press.

Lopes, P. N., Brackett, M. A., Nezlek, J., Schutz, A., Sellin, I., \& Salovey, P. (2004). Emotional intelligence and social interaction. Personality and Social Psychology Bulletin, 30, 1018-1034.

Luteijn, F. (1994). Personality and the quality of an intimate relationship. European Journal of Psychological Assessment, 10, 220-223.

McDonald, N. E., Ebert, P. D., \& Mason, S. E. (1986). Marital status and age as related to masculine and feminine personality dimensions and self-esteem. The Journal of Social Psychology. Published online: 30 Jun 2010. DOI: 10.1080/00224545.1987.9713694

Murray, S. L., Griffin, D. W., Rose, P., \& Bellavia, G. M. (2003). Calibrating the sociometer: The relational contingencies of self-esteem. Journal of Personality and Social Psychology, 85, 63-84. DOI: 10.1037/0022-3514.85.1.63

Murray, S. L., Holmes, J. G., \& Griffin, D. W. (2000). Self-esteem and the quest for felt security: How perceived regard regulates attachment processes. Journal of Personality and Social Psychology, 78, 478-498.

Nawaz, S., Javeed, S., Haneef, A., Tasaur, B., \& Khalid, I. (2014). Perceived social support and marital satisfaction among love and arranged marriage couples. International Journal of Academic Research and Reflection, 2, 41-50.

Neff, L. A., \& Karney, B. R. (2005). Gender differences in social support: A question of skill or responsiveness? Journal of Personality and So- 
cial Psychology, 88, 79-90. DOI: 10.1037/00223514.88.1.79

Prager, K. J. (2000). Intimacy in personal relationships. In C. Hendrick \& S. S. Hendrick (Eds.), Close relationships: $A$ sourcebook (pp. 229-242). Thousand Oaks, CA, US: Sage Publications.

Pugliesi, K. L. (1985). The Well-being of women: The effects of marital status, employment and social support resources. Unpublished doctoral dissertation, Washington State University.

Revenson, T. A., Schiaffino, K. M., Majerovitz, S. D., \& Gibofsky, A. (1991). Social support as a double-edged sword The relation of positive and problematic support to depression among rheumatoid arthritis patients. Social Science \& Medicine, 33, 807-813. DOI: 10.1016/0277-9536(91)90385-P

Riggio, R. E., Throckmorton, B., \& DePaola, S. (1990). Social skills and self-esteem. Personality and Individual Differences, 11, 799-804. DOI: 10.1016/01918869(90)90188-W

Rosenberg, M. (1965). Society and the adolescent selfimage. Princeton, NJ: Princeton University Press.

Rosenberg, M. (1979). Conceiving the self. New York: Basic Books.

Sarwer, D. B., Thompson, J. K., Mitchell, J. E., \& Rubin, J. P. (2008). Psychological considerations of the bariatric surgery patient undergoing body contouring surgery. Plastic and Reconstructive Surgery, 121, 423-434. DOI: 10.1097/PRS.0b013e3181772aa8

Schafer, R. B., \& Keith, P. M. (2001). Self-esteem agreement in the marital relationship. The Journal of Social Psychology, 132, 5-9.

Schneider, M. G. (2000). The role of psychosocial factors in stress in infertile couples. Unpublished doctoral dissertation, University of South Florida.

Schwalbe, M. L., \& Staples, C. L. (1991). Gender differences in the sources of self-esteem. Social Psychology Quarterly, 54, 158-168. DOI: 10.2307/2786933

Segrin, C., \& Taylor, M. (2007). Positive interpersonal relationships mediate the association between social skills and psychological well-being. Personality and Individual Differences, 43, 637-646. DOI: 10.1016/j.paid.2007.01.017

Sherbourne, C. D., \& Hays, R. D. (1990). Marital status, social support and health transitions in chronic disease patients. Journal of Health \& Social Behavior, 31, 328-342.

Spitzberg, W. R., \& Cupach, B. H. (1989). Handbook of Interpersonal Competence Research. New York: Springer-Verlag.

Sprecher, S., \& Hendrick, S. (2004). Self-disclosure in intimate relationships: Associations with individual and relationship characteristics over time. Journal of Social and Clinical Psychology, 23, 857-877.

Sullivan, K. T., Pasch, L. A., Eldridge, K. A., \& Bradbury, T. N. (1998). Social support in marriage: translating research into practical applications for clinicians. The Family Journal, 6, 263-271.
Thoits, P. A. (2011). Mechanisms linking social ties and support to physical and mental health. Journal of Health and Social Behavior, 52, 145-161. http://dx.doi.org/10.1177/0022146510395592

Villa, M. B., \& Del Prette, Z. A. P. (2013). Marital satisfaction: The role of social skills of husbands and wives. Paidéia, 23, 379-387. DOI: 10.1590/198243272356201312

Wiggins, J. D., \& Lederer, D. A. (1984). Differential antecedents of infidelity in marriage. American Mental Health Counselors Association Journal, 6 , 152-161.

Yelsma, P., \& Marrow, S. (2003). An examination of couples' difficulties with emotional expressiveness and their marital satisfaction. Journal of Family Communication, 3, 41-62. DOI: 10.1207/ S15327698JFC0301_03

Yıldız, M. A., \& Baytemir, K. (2016). A mediation role of self-esteem in the relationship between marital satisfaction and life satisfaction in married individuals. The Journal of Inönü Educational Faculty, 17, 67-80.

Yüksel, G. (1997). The effect of social skill education on the level of social skills of university students. Unpublished doctoral thesis. Ankara, Gazi University Educational Sciences Institute.

Zimet, G. D., Dahlem, N. W., Zimet, S. G., \& Farley, G. K. (1988). The multidimensional scale of perceived social support. Journal of Personality Assessment, 52, 30-41. 